\title{
Numerical study on cell performance and local transport phenomena of PEM fuel cells with novel flow field designs
}

\author{
Wei-Mon Yan ${ }^{\mathrm{a}, *}$, Hui-Chung Liu ${ }^{\mathrm{a}}$, Chyi-Yeou Soong ${ }^{\mathrm{b}}$, Falin Chen ${ }^{\mathrm{c}}$, C.H. Cheng ${ }^{\mathrm{d}}$ \\ ${ }^{a}$ Department of Mechatronic Engineering, Huafan University, Shih-Ting, Taipei 223, Taiwan, ROC \\ ${ }^{\mathrm{b}}$ Department of Aerospace and Systems Engineering, Feng Chia University, Seatwen, Taichung 407, Taiwan, ROC \\ ${ }^{\mathrm{c}}$ Institute of Applied Mechanics, National Taiwan University, Taipei 106, Taiwan, ROC \\ ${ }^{\mathrm{d}}$ Department of Mechanical Engineering, Tatung University, Taipei 104, Taiwan, ROC \\ Received 13 April 2006; received in revised form 2 May 2006; accepted 3 May 2006 \\ Available online 13 June 2006
}

\begin{abstract}
In this work, a novel style of straight flow channel tapered in height or width is proposed to improve the efficiency of fuel utilization for PEM fuel cells. Fuel channels of various height and width taper ratios are numerically analyzed to understand their effects on fuel transport characteristics and cell performance. Influences of the liquid water formation on the transport phenomena and cell performance are included in the numerical model. The present results demonstrated that, with the tapered channel designs, the flow area contraction along the flow channel leads to increase in fuel velocity and thus enhances the fuel transport through porous layers, fuel utilization, and the capability of the liquid water removal. The results also reveal that the cell performance can be improved by either decreasing height taper ratio or increasing width taper ratio. If the power loss due to pressure drop is not considered, the performance of the fuel cell with the tapered flow channels is consistently improved with height taper ratios decreased and width taper ratio increased. With the pressure loss considered, however, the best performance can be obtained at the height taper ratio $\left(\Lambda_{x}\right)$ of 0.5 and the width taper ratio $\left(\Lambda_{\mathrm{z}}\right)$ of 1.8 among the taper ratios studied in the present work.
\end{abstract}

(C) 2006 Elsevier B.V. All rights reserved.

Keywords: PEM fuel cells; Novel flow field design; Electricity and mass transport

\section{Introduction}

In PEM fuel cells with conventional flow channels, reactant gases diffuse from channel inlet into catalyst layer through gas diffuser layer (GDL), and then take part in the reaction. Since the diffusion process is not helpful for removing heat and cathode water, various new styles of flow channel designs, such as serpentine, Z-type and interdigitated designs, are proposed to improve these matters.

A number of investigations were carried out on serpentine flow channel designs. Maharudrayya et al. [1] numerically analyzed the effects of Reynolds number, aspect ratio and curvature ratio of flow channels on pressure drop, and found that the overall pressure drop reduces with the number of the serpentine channels. Also by numerical analysis of fuel cells with serpentine flow channels, Nguyen et al. [2] disclosed that the

\footnotetext{
* Corresponding author. Tel.: +886 26632102; fax: +886226632143.

E-mail address: wmyan@ huafan.hfu.edu.tw (W.-M. Yan).
}

activation overpotential mainly occurs under the ribs, which implied that the Ohmic loss under the ribs is lower than that under the channels. In addition, it was indicated that the temperature at the interface between the channels and diffuser layer is $1-7^{\circ} \mathrm{C}$ higher than the operating temperature. Using a commercial codes, FLUENT, Dutta et al. [3] studied three-dimensional mass transport process, fuel concentration variation and their effects on electrochemical reaction in PEM fuel cells with serpentine flow channels.

Though serpentine flow channel design promotes fuel cell performance, it has penalty of higher pressure loss as a result of too many bends. To solve this problem, Nguyen [4] proposed interdigitated flow channel, in which baffle plates/blocks are added to conventional channels, and then the channels are divided into two parts, inlet and outlet channels. Reactant gases from the inlet channels are forced into the outlet channels through the gas diffusion layer (GDL). With the assistance of the forced convection besides diffusion, gases are compelled to pass the domain under the ribs in a shortest way. Um and Wang $[5,6]$ dealt with the effects of oxygen and vapor distributions and 


\begin{tabular}{|c|c|}
\hline \multicolumn{2}{|c|}{ Nomenclature } \\
\hline $\mathrm{Aj}_{0, \mathrm{a}}^{\mathrm{ref}}$ & exchange current density at anode side \\
\hline $\mathrm{Aj}_{0, \mathrm{c}}^{\mathrm{ref}}$ & exchange current density at cathode side \\
\hline$a$ & chemical activity of water vapor \\
\hline C & mass fraction \\
\hline$C_{\mathrm{s}}$ & saturated concentration of liquid water \\
\hline$C_{\mathrm{F}}$ & quadratic drag factor \\
\hline$C_{\phi}$ & $\begin{array}{l}\text { connected coefficient between source term and } \\
\left(\phi_{0}-\phi_{\delta}\right)\end{array}$ \\
\hline$D$ & mass diffusivity $\left(\mathrm{m}^{2} \mathrm{~s}^{-1}\right)$ \\
\hline$D_{\mathrm{H}_{2}}$ & hydrogen diffusivity \\
\hline$D_{\mathrm{O}_{2}}$ & oxygen diffusivity \\
\hline$D_{\mathrm{H}^{+}}$ & proton diffusivity in membrane \\
\hline$D_{k, \text { eff }}$ & $\begin{array}{l}\text { effective mass diffusivity for the } k \text { th species } \\
\left(\mathrm{m}^{2} \mathrm{~s}^{-1}\right)\end{array}$ \\
\hline$d_{\text {porous }}$ & equivalent surface diameter of porous media \\
\hline & Faraday constant $\left(96,487 \mathrm{C} \mathrm{mol}^{-1}\right)$ \\
\hline$H$ & height of flow field (m) \\
\hline $\mathrm{H}^{+}$ & hydrogen ion \\
\hline $\mathrm{H}_{2} \mathrm{O}$ & water \\
\hline$I_{Y}$ & local current density in the $Y$-direction $\left(\mathrm{A} \mathrm{m}^{-2}\right)$ \\
\hline$i$ & current density $\left(\mathrm{A} \mathrm{m}^{-2}\right)$ \\
\hline$j_{\mathrm{a}}$ & current density at anode side $\left(\mathrm{A} \mathrm{m}^{-2}\right)$ \\
\hline$j_{\mathrm{c}}$ & current density at cathode side $\left(\mathrm{A} \mathrm{m}^{-2}\right)$ \\
\hline$j_{0}$ & reference current density \\
\hline$k_{\mathrm{c}}$ & coefficient of water vapor condensation rate $\left(\mathrm{s}^{-1}\right)$ \\
\hline$k_{\mathrm{e}}$ & coefficient of water vapor evaporation rate \\
\hline$k_{\mathrm{p}}$ & permeability $\left(\mathrm{m}^{2}\right)$ \\
\hline$L$ & length of flow field (m) \\
\hline$M$ & mole \\
\hline$N$ & number of baffles \\
\hline$P$ & pressure (atm) \\
\hline$P_{\text {sat }}$ & saturated water vapor pressure (atm) \\
\hline$P^{\prime}$ & perturbed variation of pressure in control volume \\
\hline Power & power $\left(\mathrm{W} \mathrm{m}^{-2}\right)$ \\
\hline$q$ & source term of variable $(\phi)$ \\
\hline$R$ & universal gas constant $\left(8.314 \mathrm{~J} \mathrm{~mol}^{-1} \mathrm{~K}^{-1}\right)$ \\
\hline$S^{\prime}$ & surface area $\left(\mathrm{m}^{2}\right)$ \\
\hline$S_{\mathrm{c}}$ & corrected source term of concentration equation \\
\hline$S_{\mathrm{j}}$ & source term of phase potential equation \\
\hline$S_{\mathrm{L}}$ & source term of liquid water effect \\
\hline$S_{u}$ & $\begin{array}{l}\text { source term of momentum equation in the } \\
x \text {-direction }\end{array}$ \\
\hline$S_{v}$ & $\begin{array}{l}\text { source term of momentum equation in the } \\
y \text {-direction }\end{array}$ \\
\hline$S_{w}$ & $\begin{array}{l}\text { source term of momentum equation in the } \\
z \text {-direction }\end{array}$ \\
\hline$s$ & volume ratio occupied by liquid water \\
\hline$T$ & temperature $(\mathrm{K})$ \\
\hline$t$ & time $(s)$ \\
\hline$u$ & velocity in the $x$-direction $\left(\mathrm{m} \mathrm{s}^{-1}\right)$ \\
\hline$V^{\prime}$ & volume $\left(\mathrm{m}^{3}\right)$ \\
\hline$V_{\text {cell }}$ & operating cell pressure $(\mathrm{V})$ \\
\hline$v$ & velocity in the $y$-direction $\left(\mathrm{m} \mathrm{s}^{-1}\right)$ \\
\hline
\end{tabular}

\begin{tabular}{|c|c|}
\hline$W$ & width of flow field (m) \\
\hline$w$ & velocity in the $z$-direction $\left(\mathrm{m} \mathrm{s}^{-1}\right)$ \\
\hline$X$ & mole fraction \\
\hline$x$ & velocity in the $x$-direction $\left(\mathrm{m} \mathrm{s}^{-1}\right)$ \\
\hline$y$ & velocity in the $y$-direction $\left(\mathrm{m} \mathrm{s}^{-1}\right)$ \\
\hline$Z_{\mathrm{f}}$ & spices valence \\
\hline$z$ & velocity in the $z$-direction $\left(\mathrm{m} \mathrm{s}^{-1}\right)$ \\
\hline \multicolumn{2}{|c|}{ Greek letters } \\
\hline$\varepsilon$ & porosity \\
\hline$\varepsilon_{\text {eff }}$ & effective porosity \\
\hline$\lambda$ & water content in membrane \\
\hline$v$ & kinematic viscosity $\left(\mathrm{m}^{2} \mathrm{~s}^{-1}\right)$ \\
\hline$\rho$ & density $\left(\mathrm{kg} \mathrm{m}^{-3}\right)$ \\
\hline$\eta$ & over-potential (V) \\
\hline$\sigma_{\mathrm{m}}$ & electric conductivity in membrane \\
\hline$\phi$ & dependent variables \\
\hline$\Gamma_{\phi}$ & exchange coefficient \\
\hline$\Phi$ & phase potential function \\
\hline$\Lambda_{x}$ & height tapered ratio \\
\hline$\Lambda_{z}$ & width tapered ratio \\
\hline \multicolumn{2}{|c|}{ Superscripts } \\
\hline ref & reference value \\
\hline$\tau$ & turtuosity of the pore in the porous medium \\
\hline \multicolumn{2}{|c|}{ Subscripts } \\
\hline a & anode \\
\hline CL & catalyst layer \\
\hline $\mathrm{c}$ & cathode \\
\hline channel & channel \\
\hline eff & effective \\
\hline GDL & gas diffuser layer \\
\hline $\mathrm{H}^{+}$ & hydrogen ion \\
\hline $\mathrm{H}_{2}$ & hydrogen \\
\hline $\mathrm{H}_{2} \mathrm{O}$ & water \\
\hline inlet & entrance \\
\hline$k$ & the $k$ th species of the mixture \\
\hline Mem & membrane \\
\hline $\mathrm{O}_{2}$ & oxygen \\
\hline outlet & outlet \\
\hline porous & porous medium \\
\hline sat & saturation \\
\hline total & total \\
\hline$x$ & in the $x$-direction \\
\hline$y$ & in the $y$-direction \\
\hline$z$ & in the $z$-direction \\
\hline
\end{tabular}

fuel transport on electrochemical reaction in three dimensional fuel cells with straight channels and interdigitated channels.

Kazim et al. [7] and Yi and Nguyen [8] analyzed the effects of various flow channel designs on PEM fuel cell performance, and concluded that interdigitated design is superior in accelerating chemical reaction and improving cell performance. Hu et al. $[9,10]$ considered in detail the effects of interdigitated design on 
cell performance. Their results showed that, relative to straight flow channel, interdigitated design in the cathode side causes higher oxygen concentration and lower liquid water content in the diffuser layer, but its cell performance is worse if the cathode fuel gas supplied without humidification.

Two main reasons cause water molecules appearing within the membrane. One is the electro-osmotic drag by potential gradient and the other is the back diffusion by water concentration gradient across the cell. When these two kinds of movement have the same rate, the water in the membrane lies at the equilibrium state. Okada et al. [11] developed a simple model to investigate water transport in the membrane, and their computational results indicated that the water concentration profile is influenced by the thickness and humidity of the membrane and the current density of the cell. Bussel et al. [12] divided a MEA into tens of units to establish a two-dimensional dynamical model, and studied the water formation, electro-osmosis and diffusion process in the PEM, and their effects on cell performance under various operating conditions. Mazumder and Cole [13,14] demonstrated the differences between two-dimensional and three-dimensional numerical results, and employed a simplified model to discuss the effects of liquid water on cell performance. Recently, Yan and co-workers presented a series of experimental and numerical studies about the flow field designs on the cell performance of PEM fuel cells [15-19].

As mentioned above, up to now the flow channel designs of PEM fuel cells appeared in the open literature are limited to straight, serpentine, Z-type and interdigitated designs. Basically, straight channel designs have lower capability in cell performance and liquid water removal, though their pressure drop is lower. Serpentine designs have too large pressure drop due to channel bends. Interdigitated designs also have very high pressure drop in the presence of channel blockage. Therefore, based on straight flow channels, a new style of flow field, i.e., tapered flow channel, is proposed to enhance fuel utilization efficiency at high current density. In this work, straight flow channels of taper ratio in height or width are proposed in order to improve the efficiency of fuel transport, fuel utilization, and cell performance in PEM fuel cells. For cells with this class of tapered channel designs, the effects of flow area variation along the flow channel on the fuel flow velocity, the fuel distribution, the fuel transport and utilization, the capability of the liquid water removal, and the cell performance are explored numerically.

\section{Analysis}

This work establishes a three-dimensional PEM fuel cell model to analyze its electrochemical reaction and transport phenomena of reactants in anode catalyst layer, PEM, and cathode catalyst layer in the MEA, where the reaction occurs. In other regions such as the GDL, no chemical reaction takes place. Therefore, the governing equations of this model include mass, momentum, species and electrical potential conversation equations. For simplicity, the following assumptions are made:

(1) the cell system is three-dimensional and steady;

(2) the inlet fuel is ideal gas;
Table 1

The parametric values used in this work

\begin{tabular}{ll}
\hline Length of flow channel $(L)(\mathrm{mm})$ & 141 \\
Height of channel $\left(H_{\text {channel }}\right)(\mathrm{mm})$ & 1 \\
Width of channel $(W)(\mathrm{mm})$ & 1 \\
Thickness of GDL $\left(H_{\mathrm{GDL}}\right)(\mathrm{mm})$ & 0.3 \\
Thickness of CL $\left(H_{\mathrm{CL}}\right)(\mathrm{mm})$ & 0.01 \\
Thickness of membrane $\left(H_{\mathrm{Mem}}\right)(\mathrm{mm})$ & 0.035 \\
Porosity of GDL $\left(\varepsilon_{\mathrm{GDL}}\right)$ & 0.4 \\
Porosity of CL $\left(\varepsilon_{\mathrm{CL}}\right)$ & 0.4 \\
Porosity of membrane $\left(\varepsilon_{\mathrm{Mem}}\right)$ & 0.28 \\
Permeability of GDL $\left(k_{\mathrm{p}, \mathrm{GDL}}\right)\left(\mathrm{m}^{2}\right)$ & $1.76 \times 10^{-11}$ \\
Permeability of CL $\left(k_{\mathrm{p}, \mathrm{CL}}\right)\left(\mathrm{m}^{2}\right)$ & $1.76 \times 10^{-11}$ \\
Permeability of membran $\left(k_{\mathrm{p}, \mathrm{Mem}}\right)\left(\mathrm{m}^{2}\right)$ & $1.8 \times 10^{-18}$ \\
Electric conductivity of GDL $\left(\Omega^{-1} \mathrm{~m}^{-1}\right)$ & 53 \\
Electric conductivity of CL $\left(\Omega^{-1} \mathrm{~m}^{-1}\right)$ & 53 \\
Reference current density in anode side $\left(\mathrm{Aj}_{0, \mathrm{a}}^{\mathrm{ref}}\right)\left(\mathrm{A} \mathrm{m}^{-3}\right)$ & $9.23 \times 10^{8}$ \\
Reference current density in cathode side $\left(\mathrm{Aj}_{0, \mathrm{c}}^{\text {ref }}\right)\left(\mathrm{A} \mathrm{m}^{-3}\right)$ & $1.05 \times 10^{6}$ \\
\hline
\end{tabular}

(3) the system is isothermal;

(4) the flow is laminar;

(5) the fluid is incompressible;

(6) the thermal properties are constant; and

(7) the porous layers such as GDL, catalyst layer and PEM are isotropic.

To reduce the time cost of three-dimensional cell computation, small scale fuel cell models were adopted by most associated literature. However, due to their short flow channels, the results hardly agreed with the general performance of the cells at a large scale. This work aims to establish a relatively large fuel cell model with the area of $14.1 \times 14.1 \mathrm{~cm}^{2}$. The geometrical dimensions and physical properties of its flow channels are listed in Table 1. Considering the symmetry nature of the fuel cell configuration as shown in Fig. 1, only the essential part of the fuel cell model is taken as the computational domain for saving the computational time. The schematic diagram of the three-dimensional tapered flow channel designs is depicted in Fig. 2. Two parameters, height taper ratio $\Lambda_{x}$ and width taper ratio $\Lambda_{z}$, are defined as follows:

$\Lambda_{x}=\frac{H_{\text {outlet }}}{H_{\text {inlet }}}, \quad \Lambda_{z}=\frac{W_{\text {outlet }}}{W_{\text {inlet }}}$

where $H_{\text {outlet }}, H_{\text {inlet }}, W_{\text {outlet }}$, and $W_{\text {inlet }}$ are the outlet height, inlet height, outlet width, and inlet width, respectively.

The governing equations under the assumptions mentioned above can be depicted as follows:

continuity equation:

$\frac{\partial u}{\partial x}+\frac{\partial v}{\partial y}+\frac{\partial w}{\partial z}=0$.

momentum equation $(x)$ :

$\varepsilon_{\text {eff }}\left(u \frac{\partial u}{\partial x}+v \frac{\partial u}{\partial y}+w \frac{\partial u}{\partial z}\right)$
$=-\frac{\varepsilon_{\text {eff }}}{\rho} \frac{\partial P}{\partial x}+v \varepsilon_{\text {eff }}\left(\frac{\partial^{2} u}{\partial x^{2}}+\frac{\partial^{2} u}{\partial y^{2}}+\frac{\partial^{2} u}{\partial z^{2}}\right)+S_{u}$ 


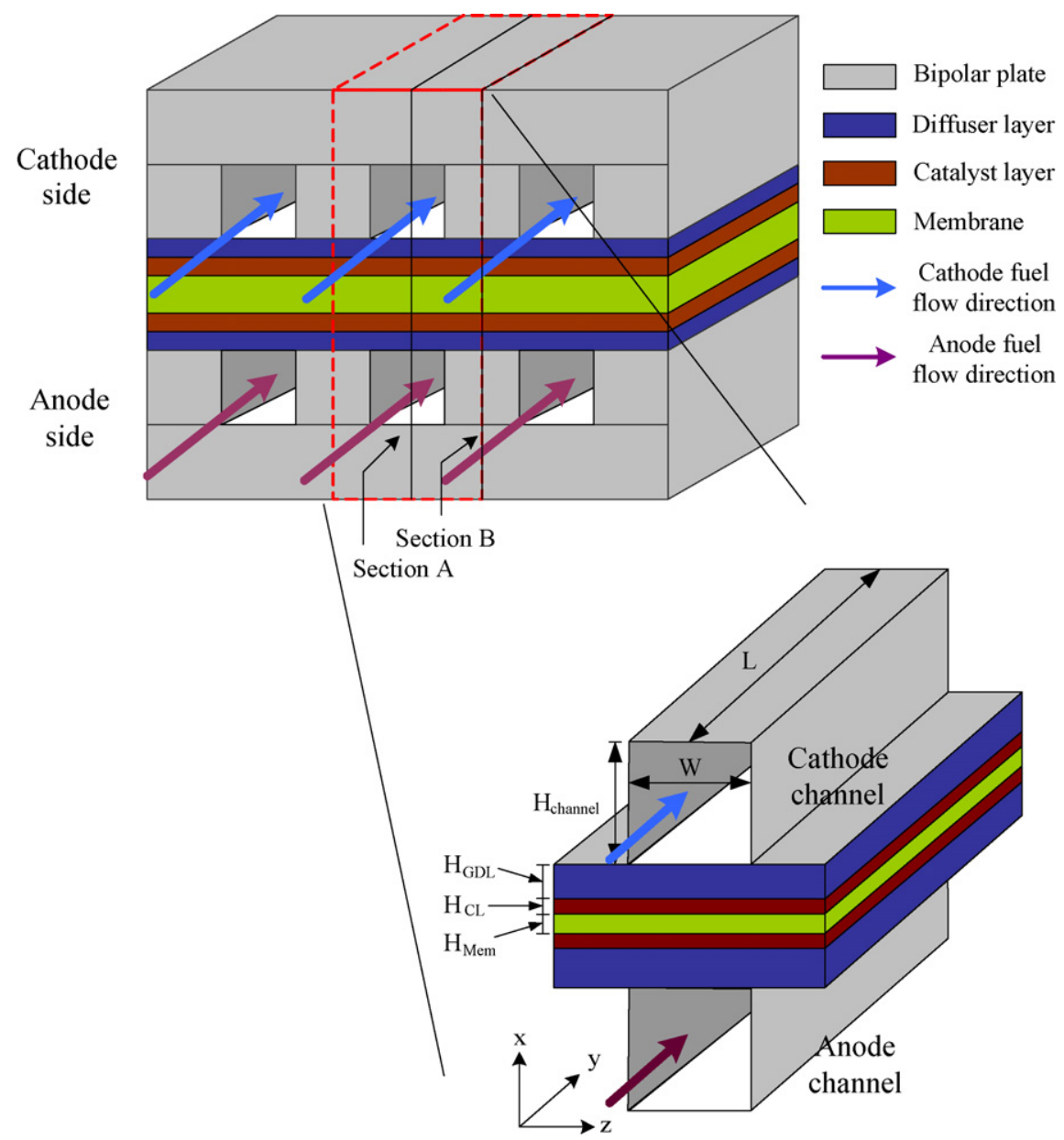

Fig. 1. Schematic diagram of the three dimensional model.

momentum equation $(y)$ :

$$
\begin{aligned}
& \varepsilon_{\mathrm{eff}}\left(u \frac{\partial v}{\partial x}+v \frac{\partial v}{\partial y}+w \frac{\partial v}{\partial z}\right) \\
& =-\frac{\varepsilon_{\mathrm{eff}}}{\rho} \frac{\partial P}{\partial y}+v \varepsilon_{\mathrm{eff}}\left(\frac{\partial^{2} v}{\partial x^{2}}+\frac{\partial^{2} v}{\partial y^{2}}+\frac{\partial^{2} v}{\partial z^{2}}\right)+S_{v}
\end{aligned}
$$

momentum equation $(z)$ :

$$
\begin{aligned}
& \varepsilon_{\text {eff }}\left(u \frac{\partial w}{\partial x}+v \frac{\partial w}{\partial y}+w \frac{\partial w}{\partial z}\right) \\
& =-\frac{\varepsilon_{\text {eff }}}{\rho} \frac{\partial P}{\partial z}+v \varepsilon_{\text {eff }}\left(\frac{\partial^{2} w}{\partial x^{2}}+\frac{\partial^{2} w}{\partial y^{2}}+\frac{\partial^{2} w}{\partial z^{2}}\right)+S_{w}
\end{aligned}
$$

In various layers, $S_{u}, S_{v}$ and $S_{w}$ denote different source terms, whose details are listed in Table 2. In PEM, $S_{u}, S_{v}$ and $S_{w}$ embody the proton transport and the liquid water dragged by electro-osmosis. In Table $1, \varepsilon_{\text {eff }}$ is the effective porosity of porous material, $C_{\mathrm{F}}$ the quadratic drag factor, and $Z_{\mathrm{f}}$ the ion valence in PEM. In addition, $D_{k \text {,eff }}$ is the effective diffusion coefficient of the $k$ th speices, which is calculated by the Bruggerman equation [20], and $k_{\mathrm{p}}$ is the permeability in porous material, and its dependence of porosity can be described by
Blake-Kozeny equation [21],

$k_{\mathrm{p}}=\left(\frac{d_{\text {porous }}^{2}}{150}\right)\left[\frac{\varepsilon^{3}}{(1-\varepsilon)^{2}}\right]$

where $d_{\text {porous }}$ is the equivalent area of porous material and expressed in the from of

$d_{\text {porous }}=\frac{6 V_{\text {porous }}^{\prime}}{S_{\text {porous }}^{\prime}}$

Species equation ( $k$ th species):

$$
\begin{aligned}
& \varepsilon_{\text {eff }}\left(u \frac{\partial C_{k}}{\partial x}+v \frac{\partial C_{k}}{\partial y}+w \frac{\partial C_{k}}{\partial z}\right) \\
& =D_{k, \text { eff }}\left(\frac{\partial^{2} C_{k}}{\partial x^{2}}+\frac{\partial^{2} C_{k}}{\partial y^{2}}+\frac{\partial^{2} C_{k}}{\partial z^{2}}\right)+S_{c}+S_{L}
\end{aligned}
$$

where $C_{k}$ is the concentration of $k$ th species, and $S_{\mathrm{c}}$ is the source term in the catalyst layers with the correction by chemical reaction. It is of the form $-j_{\mathrm{a}} / 2 F C_{\text {total, } \mathrm{a}}$ for hydrogen, $-j_{\mathrm{c}} / 4 F C_{\text {total,c }}$ for oxygen, and $-j_{\mathrm{c}} / 2 F C_{\text {total,c }}$ for vapor. In these expressions, $j_{\mathrm{a}}$ and $j_{\mathrm{c}}$, respectively, denote the current densities on anode side and cathode side, and can be calculated by the following 


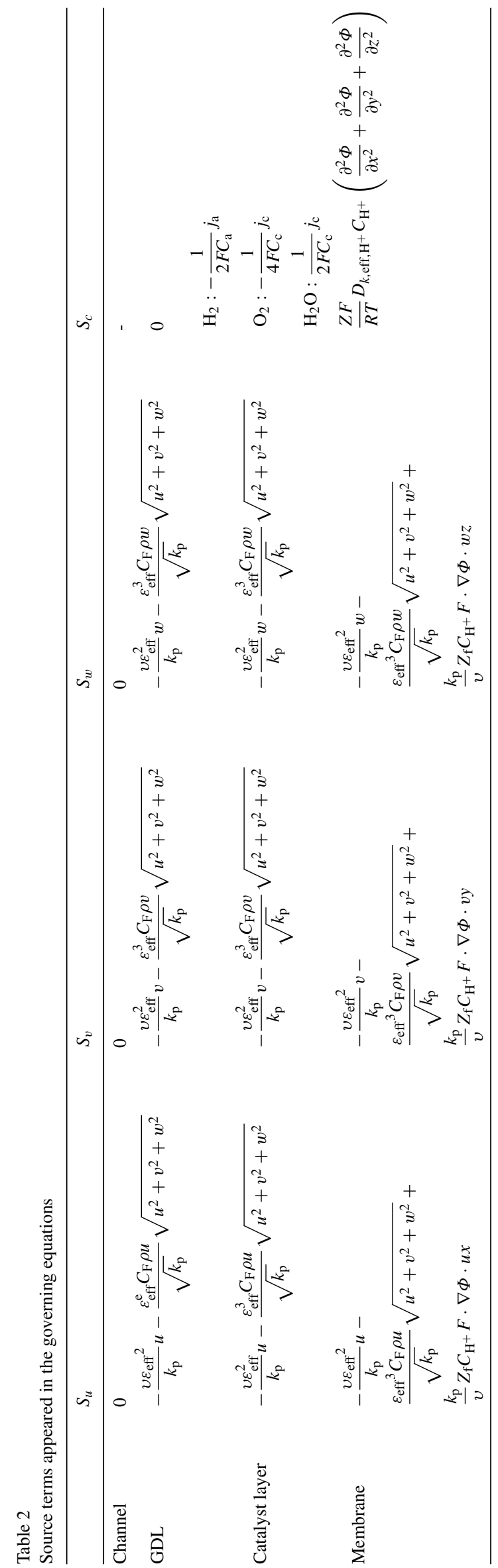

equations:

$$
\begin{aligned}
& j_{\mathrm{a}}=\mathrm{Aj}_{0}^{\mathrm{ref}}\left(\frac{C_{\mathrm{H}_{2}}}{C_{\mathrm{H}_{2}}^{\mathrm{ref}}}\right)\left[\mathrm{e}^{\left(\alpha_{\mathrm{a}} F / R T\right) \eta}-\frac{1}{\mathrm{e}^{\left(\alpha_{\mathrm{c}} F / R T\right) \eta}}\right] \\
& j_{\mathrm{c}}=\mathrm{Aj}_{0}^{\mathrm{ref}}\left(\frac{C_{\mathrm{O}_{2}}}{C_{\mathrm{O}_{2}}^{\mathrm{ref}}}\right)\left[\mathrm{e}^{\left(\alpha_{\mathrm{a}} F / R T\right) \eta}-\frac{1}{\mathrm{e}^{\left(\alpha_{\mathrm{c}} F / R T\right) \eta}}\right]
\end{aligned}
$$

Besides the continuity, momentum, and energy equations, the phase potential equation for potential and current profile is

$$
\frac{\partial}{\partial x}\left(\sigma_{\mathrm{m}} \frac{\partial \Phi}{\partial x}\right)+\frac{\partial}{\partial y}\left(\sigma_{\mathrm{m}} \frac{\partial \Phi}{\partial y}\right)+\frac{\partial}{\partial z}\left(\sigma_{\mathrm{m}} \frac{\partial \Phi}{\partial z}\right)=S_{j}
$$

where $\Phi$ is the phase potential function, and $\sigma_{\mathrm{m}}$ is the membrane conductivity and is expressed as below according to Springer et al. [22] and Nguyen and White [23].

$\sigma_{\mathrm{m}}(T)=\sigma_{\mathrm{m}}^{\mathrm{ref}} \exp \left[1268\left(\frac{1}{303}-\frac{1}{T}\right)\right]$

where $\sigma_{\mathrm{m}}^{\mathrm{ref}}$ is the reference conductivity of membrane, and is expressed as follows:

$\sigma_{\mathrm{m}}^{\mathrm{ref}}=0.005139 \lambda-0.00326$

$\lambda= \begin{cases}0.043+17.81 a-39.85 a^{2}+36.0 a^{3} & 0 \leq a \leq 1 \\ 14+1.4(a-1) & 1<a \leq 3\end{cases}$

in which $a$ denotes the vapor activity and $\lambda$ the water content in PEM, $S_{\mathrm{j}}$ in Eq. (10) is the electricity source, which is zero in the PEM without electrochemical reaction and is $-j_{\mathrm{a}}$ or $-j_{\mathrm{c}}$ on the cathode or anode side. The relationship between the phase potential $\Phi$ and the current density $i$ is expressed as below:

$i_{x}=-\sigma_{\mathrm{m}} \frac{\partial \Phi}{\partial x}$

$i_{y}=-\sigma_{\mathrm{m}} \frac{\partial \Phi}{\partial y}$

$i_{z}=-\sigma_{\mathrm{m}} \frac{\partial \Phi}{\partial y}$

Thereby, the phase potential equation can be reduced to the following equation:

$\frac{\partial i_{x}}{\partial x}+\frac{\partial i_{y}}{\partial y}+\frac{\partial i_{z}}{\partial z}=S_{\mathrm{j}}$

As another important issue of this model, the effects of liquid water are simplified. Although there is no two-phase flow behavior included in the model, the blockage effects with the presence of liquid water in the pores of porous layers such as the GDL, catalyst layer and PEM, are taken into account. The source term $S_{\mathrm{L}}$ in the species equations is expressed to be the water amount of condensation or evaporation, and is evaluated as:

$$
S_{\mathrm{L}}= \begin{cases}M_{\mathrm{H}_{2} \mathrm{O}} k_{\mathrm{c}} \frac{\varepsilon_{\mathrm{eff}} C_{\mathrm{H}_{2} \mathrm{O}}}{\rho R T}\left(P_{\mathrm{H}_{2} \mathrm{O}}-P_{\text {sat }}\right), & \text { if } P_{\mathrm{H}_{2} \mathrm{O}}>P_{\text {sat }} \\ k_{\mathrm{e}} \varepsilon_{\mathrm{eff}} s\left(P_{\mathrm{sat}}-P_{\mathrm{H}_{2} \mathrm{O}}\right), & \text { if } P_{\mathrm{H}_{2} \mathrm{O}}<P_{\text {sat }}\end{cases}
$$



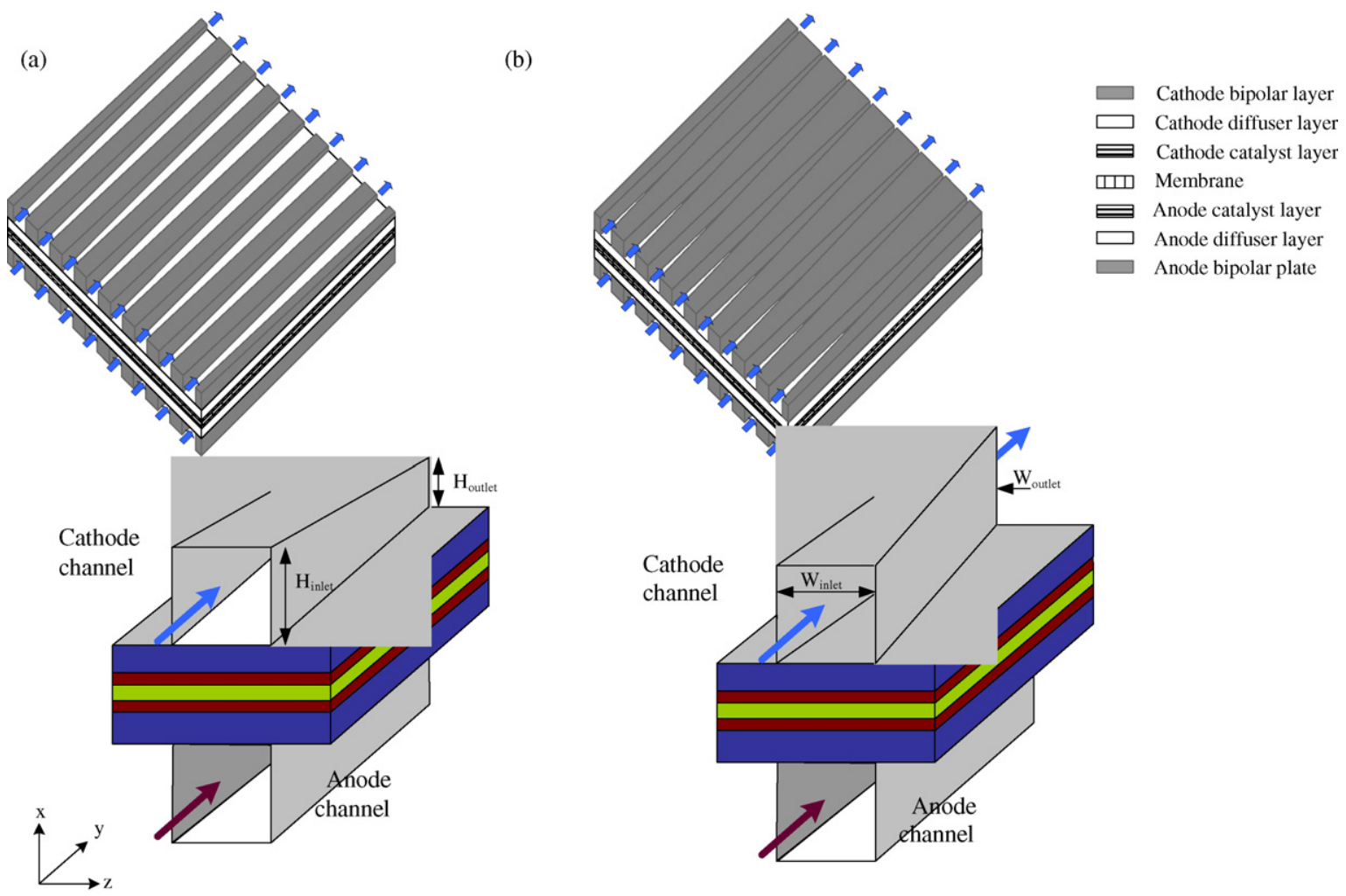

Fig. 2. Schematic diagrams of the tapered channel designs: (a) flow channel tapered in height; (b) flow channel tapered in width.

where $M$ is the molar weight, $k_{\mathrm{c}}$ and $k_{\mathrm{e}}$ the vapor condensation and evaporation constant, and $P_{\text {sat }}$ the vapor saturated pressure, which is calculated as follows [16-18]:

$P_{\text {sat }}=10^{-2.1794+0.02953 T-9.1837 \times 10^{-5} T^{2}+1.4454 \times 10^{-7} T^{3}}$

where $s$ denotes the volume ratio of liquid water to pore of the porous material, and that is,

$s=\frac{\text { volume of liquid water }}{\text { volume of pore }}$.

Liquid water affects the effective porosity of porous layers, which is expressed as below:

$\varepsilon_{\text {eff }}=\varepsilon(1-s)$

\subsection{Boundary conditions}

The boundary conditions of the present computational model contain those at inlet, outlet, wall, and interfaces between different layers. For comparison with the experiments, the inlet flow rates in cathode and anode flow fields are, respectively, specified to be 2000 and $4000 \mathrm{~cm}^{3} \mathrm{~min}^{-1}$, and the other specifications are listed in Table 3. At the outlet, fully developed flow is assumed and the boundary conditions of velocity and concentration can be expressed as:

$u=\frac{\partial v}{\partial y}=w=\frac{\partial C_{k}}{\partial y}=0$
At the interface between the flow channels and bipolar plates, the velocity and mass flux are zero.

$u=v=w=\frac{\partial C_{k}}{\partial z}=0$

At the interface between the flow fields and the GDLs, the velocity, mass flux, species concentration and species flux are all continuous.

$$
\begin{aligned}
& \left.\varepsilon_{\text {eff, GDL }} \frac{\partial v}{\partial x}\right|_{x=X_{\mathrm{GDL}}}=\left.\frac{\partial v}{\partial x}\right|_{x=X_{\text {channel }}},\left.\quad \varepsilon_{\mathrm{eff}, \mathrm{GDL}} \frac{\partial w}{\partial x}\right|_{x=X_{\mathrm{GDL}}} \\
& =\left.\frac{\partial w}{\partial x}\right|_{x=X_{\text {channel }}}, \quad v_{x=X_{\mathrm{GDL}}}=v_{x=X_{\text {channel }}}
\end{aligned}
$$

$\left.\varepsilon_{\text {eff,GDL }} \frac{\partial C_{k}}{\partial x}\right|_{x=X_{\mathrm{GDL}}}=\left.\frac{\partial C_{k}}{\partial x}\right|_{x=X_{\text {channel }}}$,

$C_{k, x=X_{\mathrm{GDL}}}=C_{k, x=X_{\text {channel }}}$

Table 3

The inlet conditions of fuel gases used in this work

\begin{tabular}{lll}
\hline & Anode side & Cathode side \\
\hline Inlet velocity $\left(\mathrm{m} \mathrm{s}^{-1}\right)$ & 0.475 & 0.95 \\
Fuel & $\mathrm{H}_{2}, \mathrm{H}_{2} \mathrm{O}$ & $\mathrm{O}_{2}, \mathrm{H}_{2} \mathrm{O}, \mathrm{N}_{2}$ \\
Relative humidity $(\%)$ & 100 & 100 \\
Temperature $\left({ }^{\circ} \mathrm{C}\right)$ & 50 & 50 \\
\hline
\end{tabular}


At the interface between the GDLs and the catalyst layers, the velocity and concentration conditions are similar to those at the interface between the flow fields and the GDLs.

$$
\begin{aligned}
& \left.\varepsilon_{\mathrm{eff}, \mathrm{CL}} \frac{\partial v}{\partial x}\right|_{x=X_{\mathrm{CL}}}=\left.\varepsilon_{\mathrm{eff}, \mathrm{GDL}} \frac{\partial v}{\partial x}\right|_{x=X_{\mathrm{GDL}}}, \\
& \left.\varepsilon_{\mathrm{eff}, \mathrm{CL}} \frac{\partial w}{\partial x}\right|_{x=X_{\mathrm{CL}}}=\left.\varepsilon_{\mathrm{eff}, \mathrm{GDL}} \frac{\partial w}{\partial x}\right|_{x=X_{\mathrm{GDL}}}, \\
& v_{x=X_{\mathrm{CL}}}=v_{x=X_{\mathrm{GDL}}}, \quad w_{x=X_{\mathrm{CL}}}=w_{x=X_{\mathrm{GDL}}}
\end{aligned}
$$

$$
\left.\varepsilon_{\mathrm{eff}, \mathrm{CL}} \frac{\partial C_{k}}{\partial x}\right|_{x=X_{\mathrm{CL}}}=\left.\varepsilon_{\mathrm{eff}, \mathrm{GDL}} \frac{\partial C_{k}}{\partial x}\right|_{x=X_{\mathrm{GDL}}},
$$$$
C_{k, x=X_{\mathrm{CL}}}=C_{k, x}=X_{\mathrm{GDL}}
$$

Also, at the interfaces between the catalyst layers and PEM, as gases cannot permeate PEM, their velocity, mass flux, species concentration and species flux are all zero.

$$
\begin{aligned}
& \left.\varepsilon_{\text {eff,CL }} \frac{\partial v}{\partial x}\right|_{x=X_{\mathrm{CL}}}=0,\left.\quad \varepsilon_{\mathrm{eff}, \mathrm{CL}} \frac{\partial w}{\partial x}\right|_{x=X_{\mathrm{CL}}}=0, \\
& v_{x=X_{\mathrm{CL}}}=0
\end{aligned}
$$

$\left.\varepsilon_{\mathrm{eff}, \mathrm{CL}} \frac{\partial C_{k}}{\partial x}\right|_{x=X_{\mathrm{CL}}}=0, \quad C_{k, x=X_{\mathrm{CL}}}=0$

Since liquid water can transport through the PEM as a result of the influences of proton transport and electro-osmosis, its velocity, mass flux, liquid water saturation degree $C_{\mathrm{s}}$ and its flux is continuous at the interfaces between the catalyst layers and the PEM.

$$
\begin{aligned}
& \left.\varepsilon_{\mathrm{eff}, \mathrm{Mem}} \frac{\partial v}{\partial x}\right|_{x=X_{\mathrm{Mem}}}=\left.\varepsilon_{\mathrm{eff}, \mathrm{CL}} \frac{\partial v}{\partial x}\right|_{x=X_{\mathrm{CL}}}, \\
& \left.\varepsilon_{\text {eff,Mem }} \frac{\partial w}{\partial x}\right|_{x=X_{\text {Mem }}}=\left.\varepsilon_{\text {eff,CL }} \frac{\partial w}{\partial x}\right|_{x=X_{\mathrm{CL}}}, \\
& v_{x=X_{\mathrm{Mem}}}=v_{x=X_{\mathrm{CL}}}, \quad w_{x=X_{\mathrm{Mem}}}=w_{x=X_{\mathrm{CL}}} \\
& \left.\varepsilon_{\text {eff,Mem }} \frac{\partial C_{\mathrm{s}}}{\partial x}\right|_{x=X_{\mathrm{Mem}}}=\left.\varepsilon_{\mathrm{eff}, \mathrm{CL}} \frac{\partial C_{\mathrm{s}}}{\partial x}\right|_{x=X_{\mathrm{CL}}}, \\
& C_{\mathrm{s}, x=X_{\mathrm{Mem}}}=C_{\mathrm{s}, x=X_{\mathrm{CL}}}
\end{aligned}
$$

The boundary conditions of potential at the interface between the anode catalyst layers and the PEM is $\Phi=0$, and that at the interface between the cathode catalyst layer and the PEM can be expressed as $\partial \Phi / \partial x=\partial \Phi / \partial z=0$.

The general convection-diffusion equation can be expressed in a conservative form as follows:

$$
\frac{\partial}{\partial t}(\rho \phi)+\nabla \cdot\left(\rho \vec{u} \phi-\Xi_{\phi} \nabla \phi\right)=S_{\phi}
$$

where $t$ is the time, $\phi$ general dependent variable, such as velocity components, concentration, $\Xi_{\phi}$ exchange coefficient such as viscosity, diffusion coefficient, $S_{\phi}$ source term such as pressure gradient, $\vec{u}$ velocity vector and $\rho$ is the density.

When Eq. (32) is integrated over a control volume, a finitevolume equation can be resulted in as

$a_{\mathrm{p}} \phi_{\mathrm{p}}=a_{\mathrm{E}} \phi_{\mathrm{E}}+a_{\mathrm{W}} \phi_{\mathrm{W}}+a_{\mathrm{N}} \phi_{\mathrm{N}}+a_{\mathrm{S}} \phi_{\mathrm{S}}+a_{\mathrm{H}} \phi_{\mathrm{H}}+a_{\mathrm{L}} \phi_{\mathrm{L}}+b$

where $\phi_{\mathrm{p}}$ is the value of variable $\phi$ at node $\mathrm{P}$ of control volume, $\phi_{\mathrm{E}}, \ldots, \phi_{\mathrm{L}}$ value of variable at node of neighboring control volume, $a_{\mathrm{P}}, \ldots, a_{\mathrm{L}}$ coefficients in discretized equations and $b$ is the expression of source for the discretized equation of variable $\phi$.

The Semi Implicit Method for Pressure-Linked Equation (SIMPLE) algorithm, developed by Patankar [24], is employed to solve the governing equations.

\section{Results and discussion}

The validation of the numerical results is performed by comparing the present predictions with previous experimental results. Fig. 3 shows the comparison of the numerical and experimental results of the cell performance, i.e., the operation voltage $V_{\text {cell }}$ versus the current density of fuel cells $I\left(\mathrm{~A} \mathrm{~m}^{-2}\right)$, at the operating conditions of fully humidified fuel gases with flow rate of $4000 \mathrm{~cm}^{3} \mathrm{~min}^{-1}$, pressure of $1 \mathrm{~atm}$, and humidifying and operating temperatures of $50^{\circ} \mathrm{C}$. The solid circles denote the experimental results of Cheng [25] and the curve is the present numerical prediction. The numerical results show a few deviations from the measurements at low and high current density regimes. Since in the numerical model the presence of the liquid water is assumed to cause only the effects of blocking pores and hindering fuel transport. This is different from the complicated two-phase transport phenomena in a real case. At high current, the numerical analysis with a simplified model underestimates the liquid water effects and the model is not appropriate to simulate the real dead-zone condition. Nevertheless, the discrepancy of the cell performance between the numerical predictions and

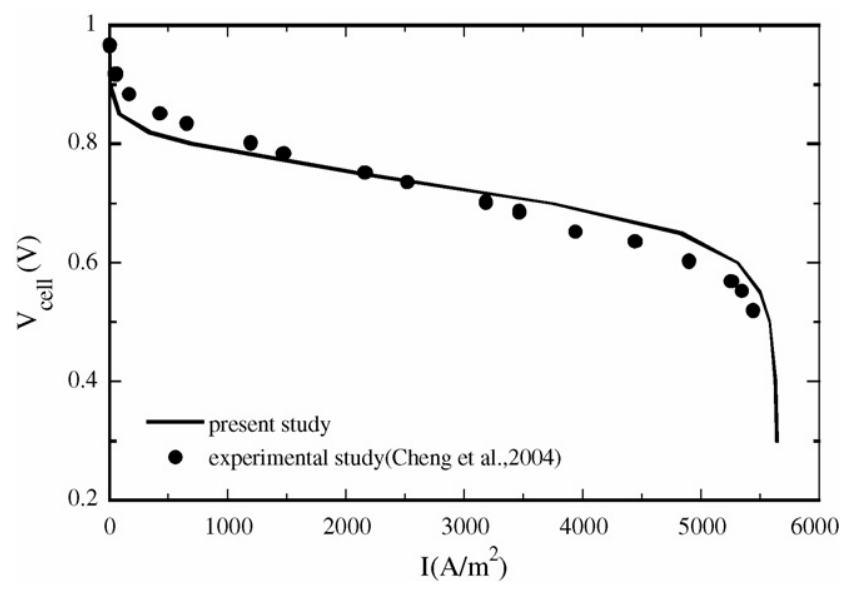

Fig. 3. Comparison of the numerical predictions with the experimental results. 


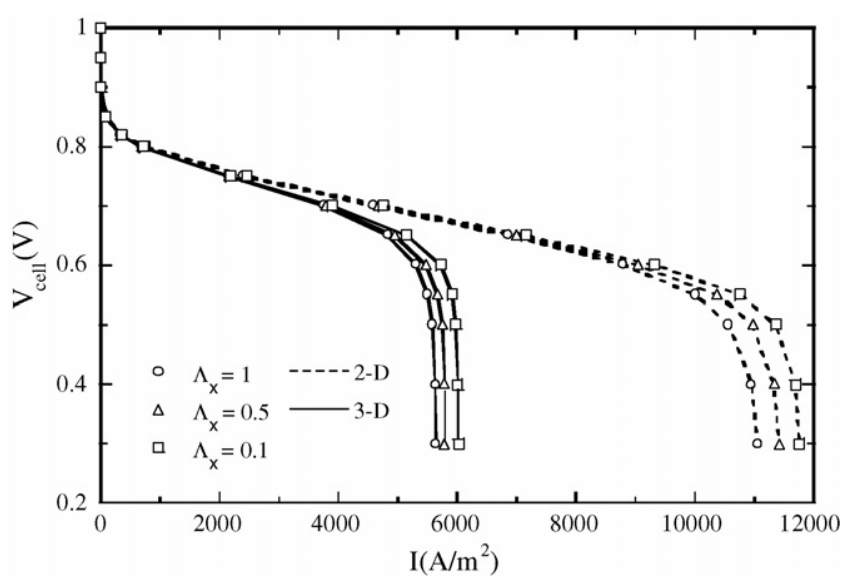

Fig. 4. Effects of tapered channel design in 2-D and 3-D models on the $I-V$ curves.

the experimental results lies within a reasonable range. Thereby it can be deduced that the present numerical method is appropriately valid in simulation of the three-dimensional fuel cells with the presence of liquid water.

Using this numerical model, the tapered flow channel design is analyzed with the emphasis on the effects of the height taper ratio and width taper ratio on cell performance. Fig. 4 presents the effects of height taper ratio on the two-dimensional (2-D) and three-dimensional (3-D) predictions of the cell performance.
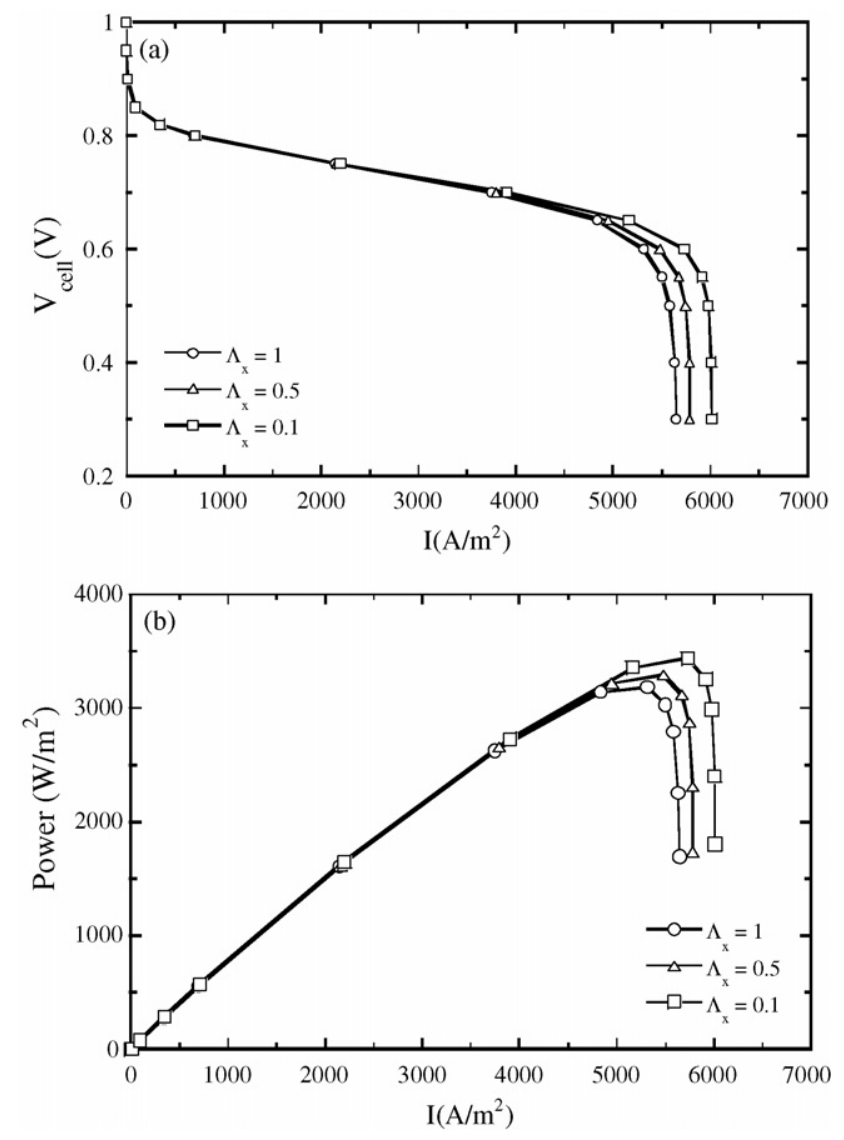

Fig. 5. Effects of height taper ratio $\Lambda_{x}$ on the cell performance. (a) $I-V$ curves; (b) $I-P$ curves.
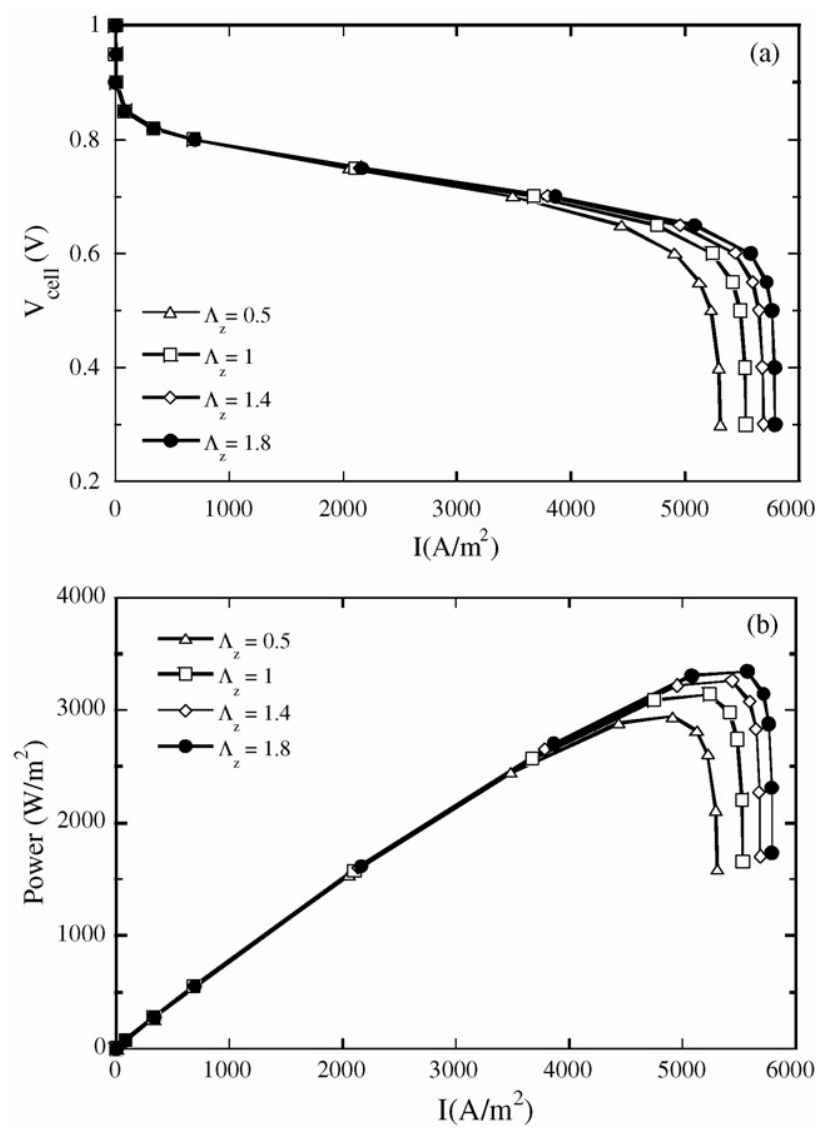

Fig. 6. Effects of width taper ratio $\Lambda_{z}$ on the cell performance. (a) $I-V$ curves; (b) $I-P$ curves.

The solid and dashed lines, respectively, denote the results of 3$\mathrm{D}$ and 2-D models. It is disclosed in Fig. 4 that, for the voltage less than $0.6 \mathrm{~V}$, the current density predicted using the 2-D model is about two times of that using the 3-D model, because the computational domain of the 2-D model is equivalently the central section of the 3-D model or section A in Fig. 1, where the current density is the maximum in the 3-D model. The diffusion path of the fuel under the ribs is longer than that under the flow channels, and part of fuel under the flow channels has participated in the reaction, so the concentration of the fuel under the ribs is lower. Since the concentration of the fuel under the ribs is low and the liquid water is difficult to be removed, the current density lowers down, and thus the current density calculated by the 3-D model are less than that by the 2-D model.

Figs. 5 and 6 present the effects of the height taper ratio $\Lambda_{x}$ and the width taper ratio $\Lambda_{z}$ on cell performance, and Fig. 5(a and $b$ ) denotes the results of $I-V_{\text {cell }}$ (current density-voltage) and $I-P$ (current density-power), respectively. At high voltage $\left(V_{\text {cell }}>0.7 \mathrm{~V}\right)$, the tapered channel design has little effects on current density for low electrochemical reaction rate. As the voltage decreases and the current density increases, the fuel amount needed rises up for more active electrochemical reaction, and the limiting condition due to lack of fuel occurs as the voltage lies at about $0.5 \mathrm{~V}$. For the lower height taper ratios in Fig. 5(a), fuel transport into GDL can be enhanced in the region near the end or the downstream portion of the flow channels, so 

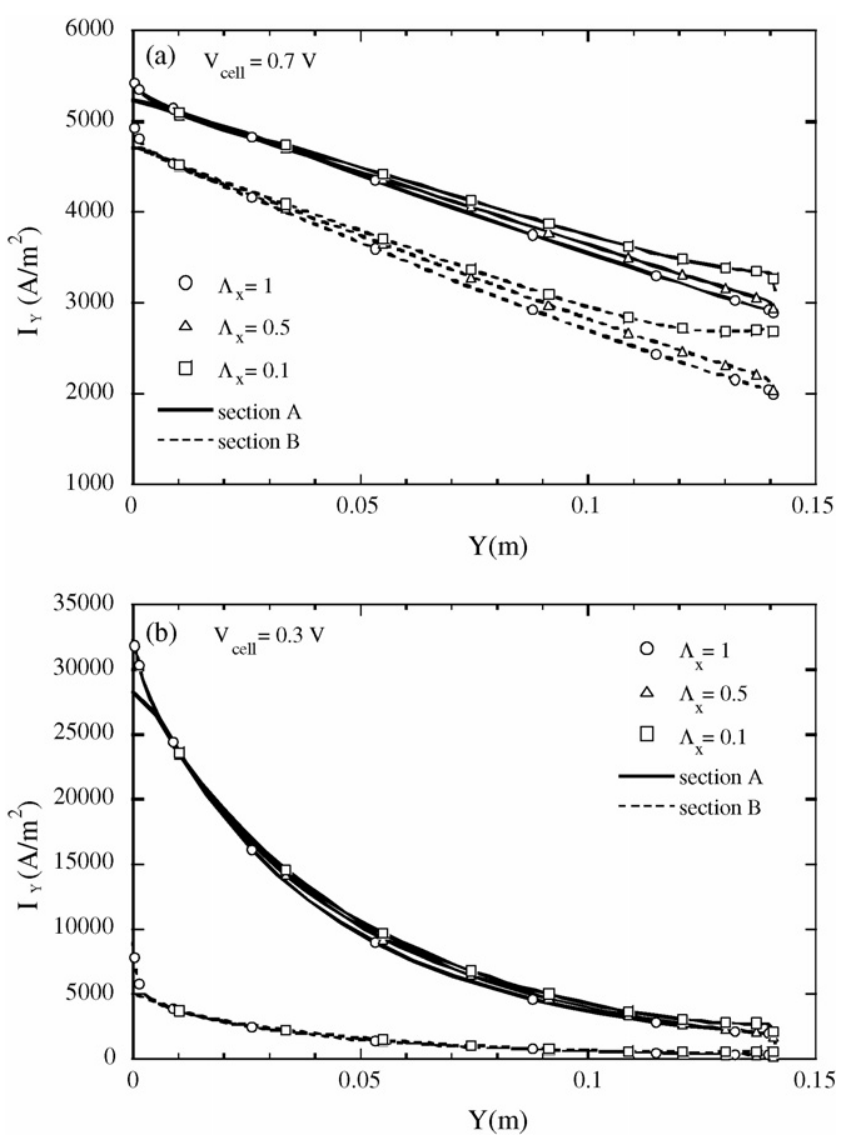

Fig. 7. Effects of height taper ratio $\Lambda_{x}$ on the local current density distributions at various cross sections of the membrane. (a) $V_{\text {cell }}=0.7 \mathrm{~V}$ and (b) $V_{\text {cell }}=0.3 \mathrm{~V}$.

the fuel amount increases and the occurrence of the fuel mass transport limit can be delayed. In addition, at a lower current density $\left(I<4000 \mathrm{~A} \mathrm{~m}^{-2}\right)$, the height taper ratio has little effects on the output power for slow electrochemical reaction, while at higher current density $\left(I>4000 \mathrm{~A} \mathrm{~m}^{-2}\right)$, a lower height taper ratio results in a higher output power. With increasing width taper ratio, the contact area between fuel and GDL rises for the area increment of the flow channels, then the content of fuel in the GDL becomes higher and, subsequently, the current density also rises. Fig. 6(b) shows the growth of the output power with the increasing width taper ratio corresponding to the cases presented in Fig. 6(a).

Figs. 7 and 8 present the effects of the height and width taper ratios on local current distributions at various sections. Along the fuel channels, the fuel amount drops due to consumption in reaction, while the liquid water as a product of the reaction accumulates. As a result, at the end of the flow channels, the fuel transport rate lowers down, and the local current density decreases along the channel $(Y$ ) direction. The data in Fig. 7(a) show that the local current density increases with the height taper ratio in the inlet region $(Y<0.02 \mathrm{~m})$, because the liquid water accumulates in this region and increases the resistance of fuel diffusion. Along the channel length, more fuel in the flow channels diffuses to the GDL and catalyst layer. This enhancement is caused by the contraction of the flow area of the fuel channels with its height tapered along the channel length. As a
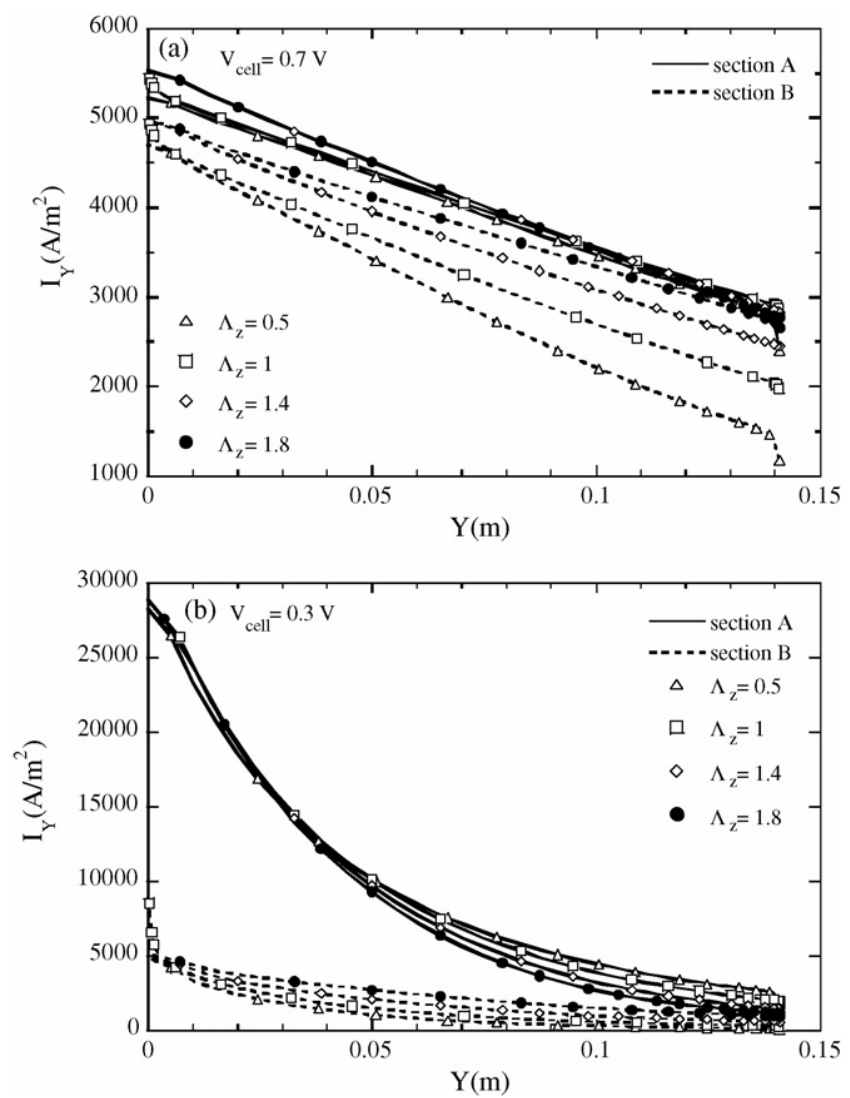

Fig. 8. Effects of width taper ratio $\Lambda_{z}$ on the local current density distributions at various cross sections of the membrane. (a) $V_{\text {cell }}=0.7 \mathrm{~V}$ and (b) $V_{\text {cell }}=0.3 \mathrm{~V}$.

result, the lower $\Lambda_{x}$ generates better current density distribution in the region of $Y>0.02 \mathrm{~m}$. In the inlet region of the flow channels of $\Lambda_{x}=0.1$, the fuel diffusion to the GDL is enhanced due to the channel taper effect, which not only increase the current density and fuel flux but also benefit the liquid water removal. At the voltage of $0.3 \mathrm{~V}$ in Fig. 7(b), the current density distribution is similar to that at $0.7 \mathrm{~V}$. However, since the electrochemical reaction at $0.3 \mathrm{~V}$ is very drastic, a large amount of fuel reacts in the region beneath the flow channels. It leads to very low current density under the ribs, so the effects of height taper ratio are not evident under the ribs.

In Fig. 8(a), the effects of the width taper ratio at the operating voltage of $0.3 \mathrm{~V}$ are quite obvious. At $\Lambda_{z}>1$, for its larger area of the flow channels, the fuel velocity is lower than that at $\Lambda_{z} \leq 1$. With an increase in the channel width, the fuel has more time to diffuse, and its diffusion path under the ribs decreases, so the difference between the current density distributions in the regions under the ribs and the channels becomes smaller. At the largest taper ratio $\Lambda_{z}=1.8$, the local current density at the outlet is almost equal to that under the flow channels. At the operating voltage of $0.3 \mathrm{~V}$, the results shown in Fig. 8(b) reveal that the local current density drops very quickly along the channel because most of the fuel takes part in the electrochemical reaction. For low width taper ratio, the fuel and the associated reaction concentrate in the central region. As a result, with a reduction in width taper ratio, the local current density under the flow channels rises, while under the ribs it decreases for 

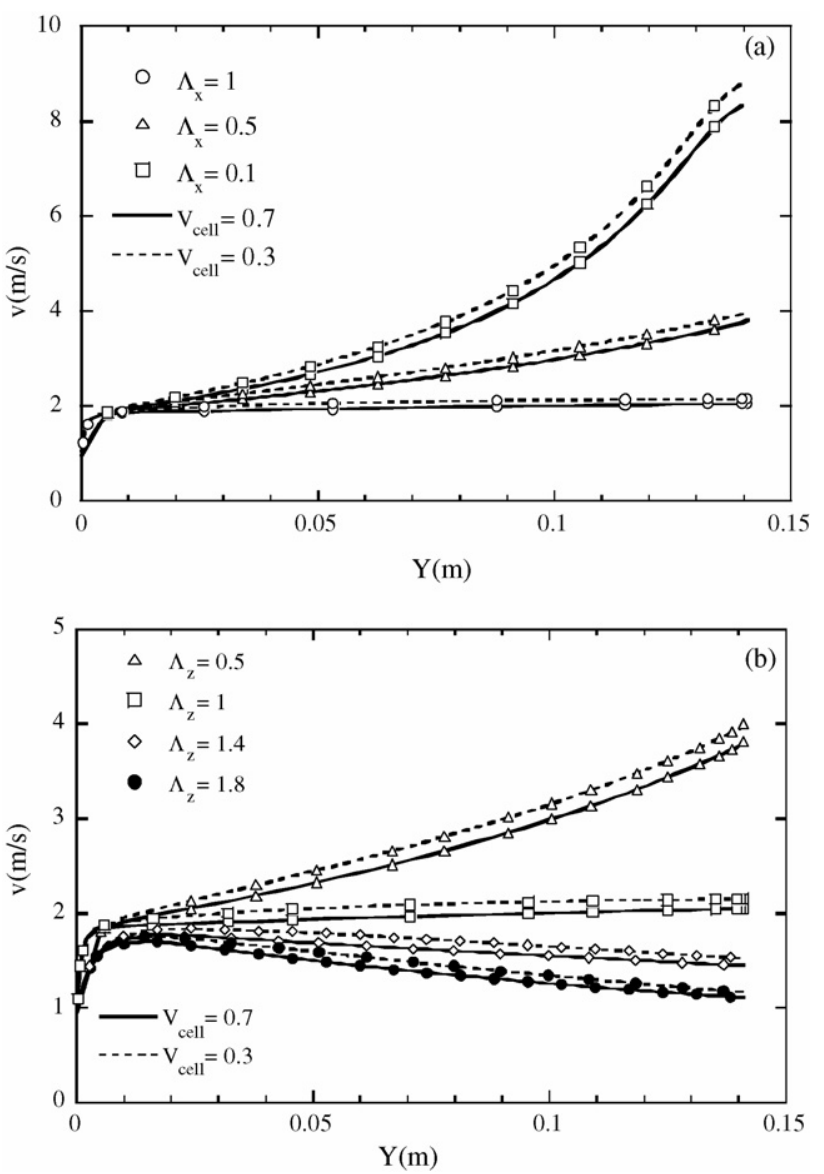

Fig. 9. Effects of tapered channel design on the velocity distributions along the cathode flow channels: (a) tapered in height; (b) tapered in width.

the effects of diffusion path. In the case of the flow channels with smaller area, the local current density under the flow channels is generally higher, while under the ribs the current density is relatively lower for the concentrated reaction under the flow channels, so larger width taper ratio produces higher current density.

The fuel velocity in the flow channels affects the liquid water removal in fuel cells. Fig. 9 presents the effects of tapered channel on the fuel velocity at the center of the channel. The effects of height and width tapered channels are shown in Fig. 9(a and b), in which the continuous and dotted lines denote the results at 0.7 and $0.3 \mathrm{~V}$, respectively. In the inlet region of the flow channels, the flow develops approaching fully developed condition, and the center-line velocity usually has a significant increment. In the baseline case of $\Lambda_{x}=1$, the velocity changes little and slightly increases along the channel for the consumption of the fuel and the decrease of the fuel density on the cathode side. For the design of height tapered flow channels, as shown in Fig. 9(a), the reduction in cross section area accelerates the fuel flow along the channels like the flow in a nozzle. This channel tapered effect becomes more remarkable as $\Lambda_{x}$ decreases. In the width tapered flow channels of $\Lambda_{z}<1$, due to nozzle effect and the fuel consumption, the fuel velocity increases along the channel, and the acceleration is more evident for lower $\Lambda_{x}$. For the flow channels of $\Lambda_{z}>1$, the center-line velocity drops along the
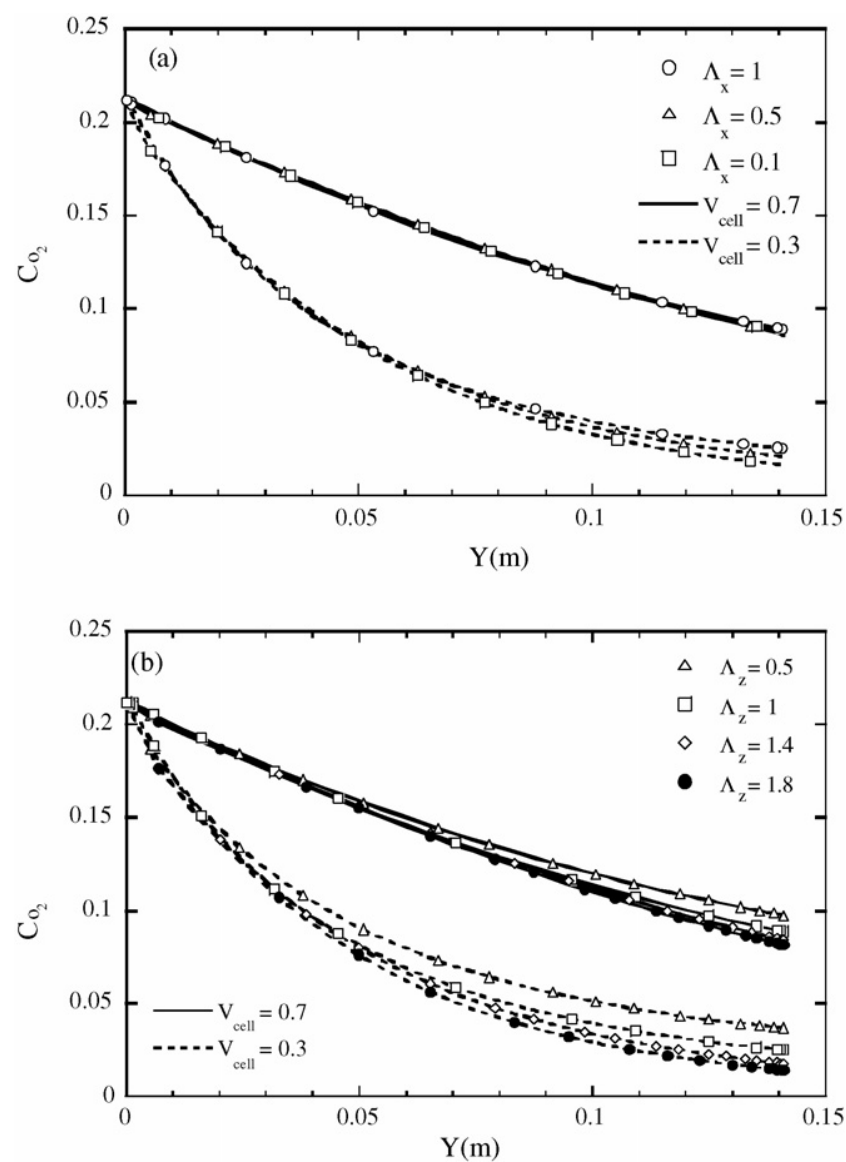

Fig. 10. Effects of tapered channel design on the oxygen distributions along the cathode flow channels: (a) tapered in height; (b) tapered in width.

flow for the increasing cross-sectional area, although the fuel consumption has somewhat influences in increasing the velocity. In the case of a lower fuel velocity, the liquid water removal caused by electrochemical reaction is difficult, but the fuel can have enough time for diffusion towards the catalyst layer. At low voltage, most oxygen participates the reaction, which results in low fuel density. Therefore, the local velocity is higher than that at a higher voltage. Moreover, this situation is more obvious as $\Lambda_{x}$ decreases.

Because the tapered flow channels are of a reduction in the channel cross sectional area, the fuel in it can be more easily to diffuse to the porous layers. Fig. 10 shows the effects of the tapered channels on fuel distributions (weight concentration of oxygen) on the cathode. Fig. 10(a and b) displays the results of the height and width tapered flow channels, respectively. At operating potential of $0.7 \mathrm{~V}$, for height tapered channels, the results in Fig. 10(a) disclose that the fuel continuously diffuses to the GDL and catalyst layer and, then, takes part in the reaction in the catalyst layer and the oxygen concentration decreases along the channel. Whereas $\Lambda_{x}$ has only little effects on the oxygen concentration for the slow electrochemical reaction. However, at a low voltage, $0.3 \mathrm{~V}$, the current density gets higher and more oxygen is consumed. Besides, the taper effects are more obvious. A smaller $\Lambda_{x}$ shows more evident taper effects and forces more fuel to reach catalyst layer and react there. It implies that 

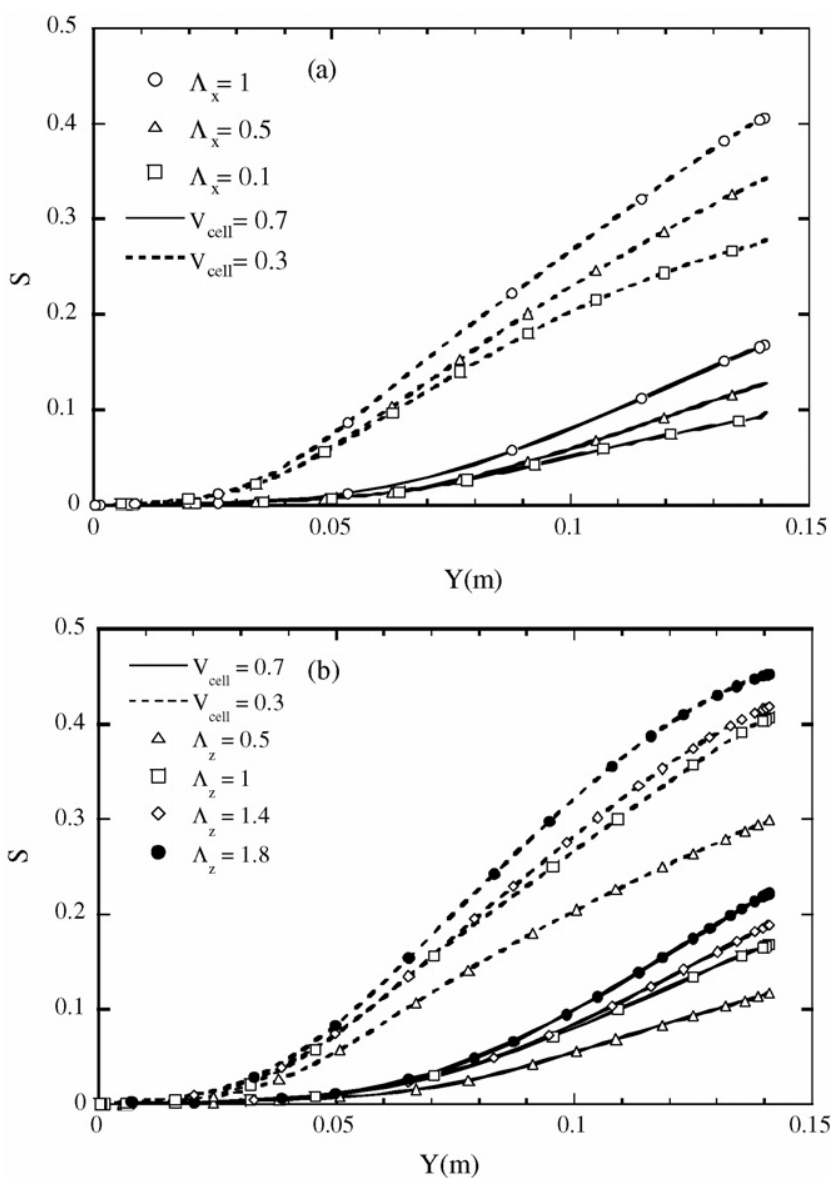

Fig. 11. Effects of tapered channel design on the liquid water distributions along the cathode flow channels: (a) tapered in height; (b) tapered in width.

the tapered channels increase the fuel utilization efficiency. For flow channels with large $\Lambda_{z}$, as shown in Fig. 10(b), the average oxygen concentration reduces due to high utilization of the fuel oxygen. It is also observed that at a high current density, the drastic electrochemical reaction consumes more oxygen, but some oxygen in the flow channels cannot transport to the catalyst layer. Since a flow channel of a large width taper ratio have relatively larger flow area, which is beneficial to the fuel utilization efficiency.

Effects of the tapered channel on the liquid water distribution in the cathode are shown in Fig. 11, in which the parameter $S$ is an index denoting the degree of the liquid water saturation. The liquid water content increases along the channel as a consequence of the electrochemical reaction. Fig. 11( $a$ and b) illustrates the effects of height taper ratio and width taper ratio, respectively. At the voltage of $0.7 \mathrm{~V}$ and the position of $Y<0.05 \mathrm{~m}$, the liquid water distribution is similar for the small taper effect. In the downstream portion of the channel, as shown in Fig. 9(a), the velocity rises in the tapered channel and more liquid water can thus be removed. As a result, in the downstream part of the channels $(Y>0.05 \mathrm{~m})$, the liquid water distribution of a tapered channel is lower than that of the regular straight channel with $\Lambda_{x}=1$. As $\Lambda_{x}=0.1$ and $Y>0.075 \mathrm{~m}$, the liquid water removal is performed well for the velocity increasing with $Y$ as a result of the large taper effect. It is shown that in this region the liquid water content rises with the increase in $\Lambda_{x}$. At $0.3 \mathrm{~V}$, the more drastic electrochemical reaction produces more liquid water than that at $0.7 \mathrm{~V}$, and the region with evident tapered effect expands from $Y>0.05 \mathrm{~m}$ to $Y>0.025 \mathrm{~m}$. Near the outlet, the taper effects are stronger, and the difference of liquid water distribution is more obvious. In Fig. 11(b), at $0.7 \mathrm{~V}$ and in the region of $Y<0.05 \mathrm{~m}$, the width of the flow channels changes little, and the liquid water produced in the catalyst layer has not permeate back to the flow channels, so the width taper ratio effects on liquid water distribution are not apparent. However, along the channel, the liquid water continuously flows in the channel and accumulates in the downstream region. For a tapered channel of $\Lambda_{z} \leq 1$, the flow velocity increases along the channel, and the liquid water is not easy to accumulate in the channel; while in a divergent channel, $\Lambda_{z}>1$, more fuel takes part in reaction and more liquid water forms. The flow velocity, as illustrated in Fig. 9(b), decreases along the channel, so the liquid water distribution increases with the increasing width taper ratio of the flow channel. These phenomena are more obvious at $0.3 \mathrm{~V}$, in which the liquid water distribution significantly increases for the high reaction rate, and it rises by $1-2$ times of that at $0.7 \mathrm{~V}$. Therefore, a smaller width taper ratio leads to better capability of liquid water removal.

The tapered channel design is beneficial to the improvement in fuel diffusion and cell performance, and it also alters the resistance of the fuel flow. In order to explore the pressure loss caused
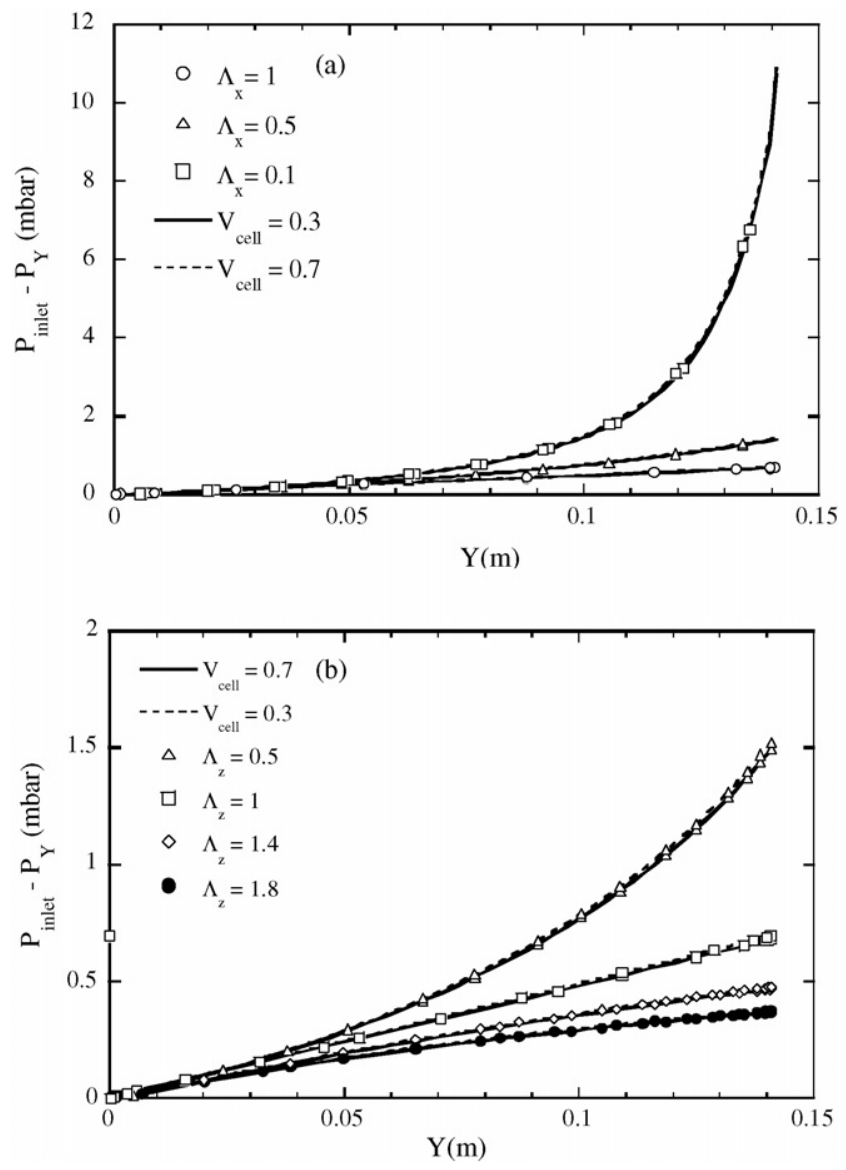

Fig. 12. Effects of tapered channel design on the pressure distributions along the cathode flow channels: (a) tapered in height; (b) tapered in width. 
by the flow area contraction in tapered channels, the local pressure losses (the difference between local and inlet pressures) at various locations of the center-line of the cathode flow channels are presented in Fig. 12. As illustrated in Fig. 12(a), the local pressure loss increases with channel length. At $\Lambda_{x}=0.5$, the difference between the inlet and outlet pressures is about two times of that at $\Lambda_{x}=1$. At $\Lambda_{x}=0.1$, the pressure loss almost rises linearly for $Y<0.08 \mathrm{~m}$, while it rises in a nonlinear manner with an increasing taper effect. As the main reason, when $\Lambda_{x}=0.1$, the height of inlet is just ten percent of the original one, and both the flow resistance and pressure loss are very large. As shown in Fig. 12(b), the design with smaller width tapered ratio of $\Lambda_{z} \leq 1$ can increase the fuel flow velocity and improve the performance of liquid water removal, but the resistance of fuel flow also increases; the design with larger width taper ratio $\Lambda_{z}>1$ increases the diffusion area of fuel, but there accumulates more liquid water in the flow channels.

\section{Conclusions}

In the present paper, the relatively novel channel design of variable cross-section has proposed and the effects of the taper ratio, either in height or width, have been analyzed in details. With this class of fuel channels, the present numerical analysis has demonstrated that the flow area variation along the flow channel leads to noticeable influences on the fuel velocity in flow channel, the capability of the liquid water removal, the fuel transport and utilization, and the cell performance. Based on the present predictions and analysis, the conclusions can be derived as follows:

1. For the cathode channels tapered in height, the reduction in outlet height is beneficial to the fuel utilization efficiency and the improvement in the cell performance.

2. For the tapered channel with the width of flow channel enlarged along the flow, the contact area of the interface between channels and GDL increases, which in turn, results in an increase in the transport rate of fuel in the outlet. Therefore, the cell performance is improved.

3. The flow channels tapered in height can enhance the fuel velocity along the flow channel, and improve the liquid water removal, whose rate increases with the decrease in height taper ratio. For the design of width tapered flow channels, the rise of the width decelerates the flow and weakens the capability of liquid water removal, while it increases the reaction efficiency and cell performance.

4. At the height taper ratio $\Lambda_{x}$ of 0.1 , the design with a large width tapered ratio weakens the taper effect. Therefore, the cell performance, the fuel velocity and the efficiency of liquid water removal are all reduced as the width taper ratio increases.

5. If the power loss due to pressure drop is not considered, the performance of the fuel cell with the tapered flow channels is consistently improved with height taper ratios decreased and width taper ratio increased. With the pressure loss considered, however, the best performance can be obtained at the height taper ratio $\left(\Lambda_{x}\right)$ of 0.5 and the width taper ratio
$\left(\Lambda_{z}\right)$ of 1.8 among the taper ratios studied in the present work.

\section{Acknowledgement}

The study was supported by the National Science Council, the Republic of China, through the grant number NSC 94-2212E-211-004.

\section{References}

[1] S. Maharudrayya, S. Jayanti, A.P. Deshpande, Pressure losses in laminar flow through serpentine channels in fuel cell stacks, J. Power Sources 138 (2004) 1-13.

[2] P.T. Nguyen, T. Berning, N. Djilali, Computational model of a PEM fuel cell with serpentine gas flow channels, J. Power Sources 130 (2004) 149157.

[3] S. Dutta, S. Shimpalee, J.W. Van Zee, Numerical prediction of mass exchange between cathode and anode channels in a PEM fuel cell, J. Heat Mass Transfer 44 (2001) 2029-2042.

[4] T.V. Nguyen, A gas distributor design for proton-exchange-membrane fuel cells, J. Electrochem. Soc. 143 (5) (1996) L103-L105.

[5] S. Um, C.Y. Wang, Three dimensional analysis of transport and reaction in proton exchange membrane fuel cells, in: The 2000 ASME International Mechanical Engineering Congress \& Exposition, Walt Disney World Dolphin, Orlando, FL, USA, November 5-10, 2000.

[6] S. Um, C.Y. Wang, Three-dimensional analysis of transport and electrochemical reactions in polymer electrolyte fuel cells, J. Power Sources 125 (2004) 40-51.

[7] A. Kazim, H.T. Liu, P. Forges, Modelling of performance of PEM fuel cells with conventional and interdigitated flow fields, J. Appl. Electrochem. 29 (1999) 1409-1416.

[8] J.S. Yi, T.V. Nguyen, Multicomponent transport in porous electrodes of proton exchange membrane fuel cells using the interdigitated gas distributors, J. Electrochem. Soc. 146 (1) (1999) 38-45.

[9] M. Hu, A. Gu, M. Wang, X. Zhu, L. Yu, Three dimensional two phase flow mathematical model for PEM fuel cell: part I. Model development, Energy Convers. Manage. 45 (2004) 1861-1882.

[10] M. Hu, A. Gu, M. Wang, X. Zhu, L. Yu, Three dimensional two phase flow mathematical model for PEM fuel cell: part II. Analysis and discussion of the internal transport mechanisms, Energy Convers. Manage. 45 (2004) 1883-1916.

[11] T. Okada, X. Gang, M. Meeg, Simulation for water management in membranes for polymer electrolyte fuel cells, Electrochim. Acta 43 (14-15) (1998) 2141-2155.

[12] H.V. Bussel, F. Koene, R. Mallant, Dynamic model of solid polymer fuel cell water management, J. Power Sources 71 (1998) 218-222.

[13] S. Mazumder, J.V. Cole, Rigorous 3-D mathematical modeling of PEM fuel cells I. Model proditions without liquid water transfer, J. Electrochem. Soc. 150 (2003) A1503-A1509.

[14] S. Mazumder, J.V. Cole, Rigorous 3-D mathematical modeling of PEM fuel cells II. Model proditions with liquid water transfer, J. Electrochem. Soc. 150 (2003) A1510-A1517.

[15] W.M. Yan, C.Y. Soong, F. Chen, H.S. Chu, Effects of flow distributor geometry and diffusion layer porosity on reactant gas transport and performance of proton exchange membrane fuel cells, J. Power Sources 125 (2004) 27-29.

[16] H.C. Liu, W.M. Yan, C.Y. Soong, F. Chen, Effects of baffle-blocked flow channel on reactant transport and cell performance of a proton exchange membrane fuel cell, J. Power Sources 142 (2005) 125-133.

[17] C.Y. Soong, W.M. Yan, C.Y. Tzeng, H.C. Liu, F. Chen, H.S. Chu, Analysis of reactant gas transport in a PEM fuel cell with partially-blocked flow channel design, J. Power Sources 143 (2005) 36-47.

[18] H.C. Liu, W.M. Yan, C.Y. Soong, F. Chen, H.S. Chu, Reactant gas transport and cell performance of proton exchange membrane fuel cells with tapered flow field design, J. Power Sources 158 (2006) 78-87. 
[19] W.M. Yan, C.H. Yang, C.Y. Soong, F. Chen, M.C. Mei, Experimental studies on optimal operating conditions for different flow field designs of PEM fuel cells, J. Power Sources 160 (2006) 284-292.

[20] W. He, J.S. Yi, T.V. Nguyen, Two phase flow model of the cathode of PEM fuel cells using interdigitated flow fields, AIChE J. 46 (10) (2000) 2053-2064.

[21] F.A.L. Dullien, Porous Media, Academic Press, New York, 1991.

[22] T.E. Springer, T.A. Zawodzinski, S. Gottesfeld, Polymer electrolyte fuel cell model, J. Electrochem. Soc. 138 (8) (1991) 2334-2342.
[23] T.V. Nguyen, R.E. White, A water and heat management model for proton-exchange-membrane fuel cells, J. Electrochem. Soc. 140 (8) (1993) $2178-2186$

[24] S.V. Patankar, Numerical Heat Transfer and Fluid Flow, Hamisphere/ McGraw-Hill, New York, 1980.

[25] C.H. Cheng, Development of shape designer for the flow channels of bipolar plate for PEM fuel cells (2/3), Technical Report of NSC-93-2212-E-036001, National Science Council, ROC, 2004. 